\title{
"Optimization of Cutting Parameters for Turning AISI 316 Stainless Steel Based on Taguchi Method"
}

\author{
J. Chandrasheker ${ }^{1}$, Mahipal Manda ${ }^{2}$, D.Vijay Kumar ${ }^{3}$ \\ ${ }^{1}$ Associate Professor (Mechanical Department, Vaageswari College of Engineering, Telangana, India) \\ ${ }^{2}$ Assistant Professor (Mechanical Department, Vaageswari College of Engineering, Telangana, India) \\ ${ }^{3}$ Assistant Professor (Mechanical Department, Vaageswari College of Engineering, Telangana, India)
}

\begin{abstract}
The objective of this work is the optimization of the cutting parameters for turning AISI 316 stainless steel to achieve the better surface finish using Taguchi's methodology. Taguchi Parameter Design is a powerful and efficient method for optimizing quality and performance output of manufacturing processes, thus a powerful tool for meeting this challenge. This work discusses an investigation into the use of Taguchi Parameter Design for optimizing surface roughness generated by a Turning operation. In this method, four control factors viz. cutting speed, feed rate, depth of cut, three different cutting fluids (sherol B, sherol ENF, straight cutting oil) and one work piece material (AISI 316 stainless steel) were investigated at three different levels and the turning operations are done on Banka 1000 lathe machine. Cutting speed followed by cutting fluid has the significant role. The quality characteristic identified is surface roughness. Experiments carried out using $L_{9}\left(3^{4}\right)$ Orthogonal Array with three different levels of control factors.The test results were analyzed using "smallerthe-better" criteria for Signal-to-Noise ratio in order to optimize the process. The experimental results were analyzed, conformed and successfully used to achieve good surface finish on work piece materials.
\end{abstract}

Keywords: Cutting parameters, turning, Surface roughness, Cutting fluids, Taguchi method.

\section{Introduction}

Turning is the removal of metal from the outer diameter of a rotating cylindrical work Piece. Turning is the machining operation that produces cylindrical parts. In its basic form, it can be defined as the machining of an external surface:

1. With the work piece rotating.

2. With a single-point cutting tool and

3. With the cutting tool feeding parallel to the axis of the work piece and at a distance that will remove the outer surface of the work.

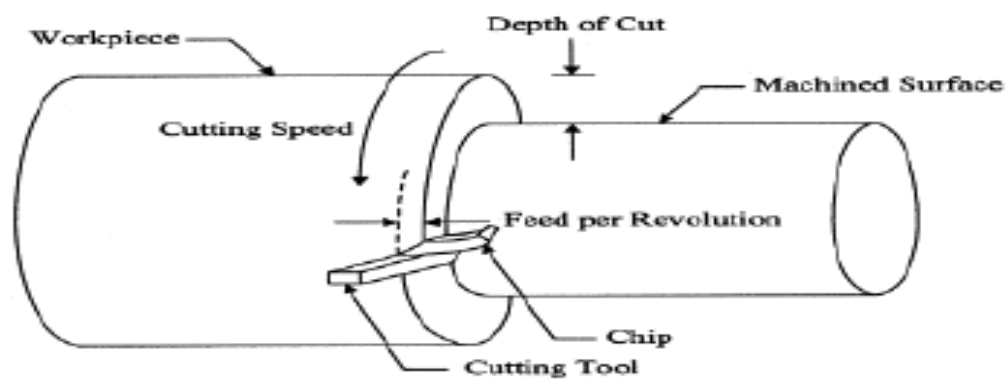

Fig- 1: Diagram for turning process

In competition industry, each manufacturing company wants to manufacture low cost and high quality product in a short time to full fill customer demand. Automated and flexible manufacturing systems are employed for that purpose along with computerized numerical control (CNC) machines that are capable of achieving high accuracy and very low processing time. In a turning operation, it is important task to select cutting parameter for achieving high cutting performance. To select the cutting parameter properly, several mathematical models and based on statistical regression or neural network techniques have been constructed to establish the relationship between the cutting performance and cutting parameter. Then, an objective function with constraints is formulated to solve the optimal cutting parameter using optimization techniques. Therefore, considerable knowledge and experience are required for this approach. In this study, an alternative approach based on the Taguchi method and is used to determine the desired cutting parameter more efficiency. 
Basically, surface roughness is strongly correlated with cutting parameters such as cutting speed, feed rate, and depth of cut. So along with these, one more cutting parameter i.e., cutting fluid is taken as the cutting parameter. Proper selection of the cutting parameters based on the parameter design of the Taguchi method is adopted in this project to improve surface roughness in a turning operation.

\subsection{Work Piece Material}

\section{Materials And Method}

The work piece material used in this project was AISI 316 Stainless Steel of length of 120mm and diameter $50 \mathrm{~mm}$. The work piece material is shown below:

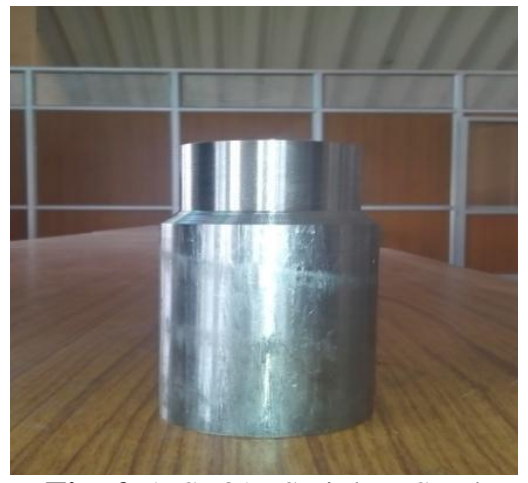

Fig -2:AISI 316 Stainless Steel

Table - 1: Chemical Composition of AISI 316 Stainless Steel.

\begin{tabular}{|l|l|l|l|l|}
\hline SNO & MATERIAL & COMPOSITION & HARDNESS \\
\hline \multirow{4}{*}{1} & AISI & C & $0.08 \% \mathrm{Max}$ & \\
& STAINLESS & Cr & $16-18 \%$ & \\
& STEEL & NI & $10-14 \%$ & $25-39 \mathrm{Hrc}$ \\
& & SI & $10 \mathrm{MAX}$ & \\
& & Mo & $2-3 \mathrm{Max}$ & \\
& & $\mathrm{Mn}$ & $2.0 \% \mathrm{Max}$ & \\
& & $\mathrm{P}$ & $0.045 \% \mathrm{Max}$ & \\
& & $\mathrm{S}$ & $0.03 \mathrm{MAX}$ & \\
\hline
\end{tabular}

\subsection{Material Applications:}

AISI 316 has improved pitting corrosion resistance and has excellent resistance to sulphates, phosphates and other salts. AISI 316 has better resistance than standard types to sea water, reducing acids and solution of chlorides, bromides and iodies. Include pumps, valves, marine fittings, fasteners, paper and pulp machinery, and petro chemical equipment.

\subsection{Cutting Tool:}

A diamond tool is a cutting tool with diamond grains fixed on the functional parts of the tool via a bonding material or another method. As diamond is a super hard material, diamond tools have many advantages as compared with tools made with common abrasives such as corundum and silicon carbide. The diamond tipped tool used in this work is show in the figure-3.

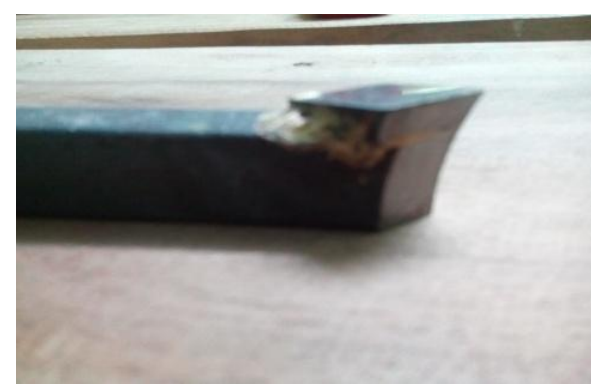

Fig -3: Diamond tipped tool

\subsection{Selection Of Control Factors:}

Cutting experiments are conducted considering four cutting parameters: Cutting Speed (m/min), feed rate $(\mathrm{mm} / \mathrm{rev})$, Depth of Cut (mm) and cutting fluids. Overall 27 experiments were carried out. Table 3 shows the values of various parameters used for experiments: 
Table - 2: Machining Parameters and Levels

\begin{tabular}{|c|c|c|c|c|}
\hline SI & \multirow[t]{2}{*}{ Process Parameter } & & Levels & \\
\hline No & & 1 & 2 & 3 \\
\hline 1 & Speed $(\mathrm{m} / \mathrm{min})$ & 500 & 1000 & 1500 \\
\hline 2 & Feed $(\mathrm{mm} / \mathrm{rev})$ & 0.10 & 0.15 & 0.20 \\
\hline 3 & Depth of Cut (mm) & 0.3 & 0.5 & 0.8 \\
\hline 4 & Cutting fluid & Sherol -B & Sherol - ENF & Straight cutting oil \\
\hline
\end{tabular}

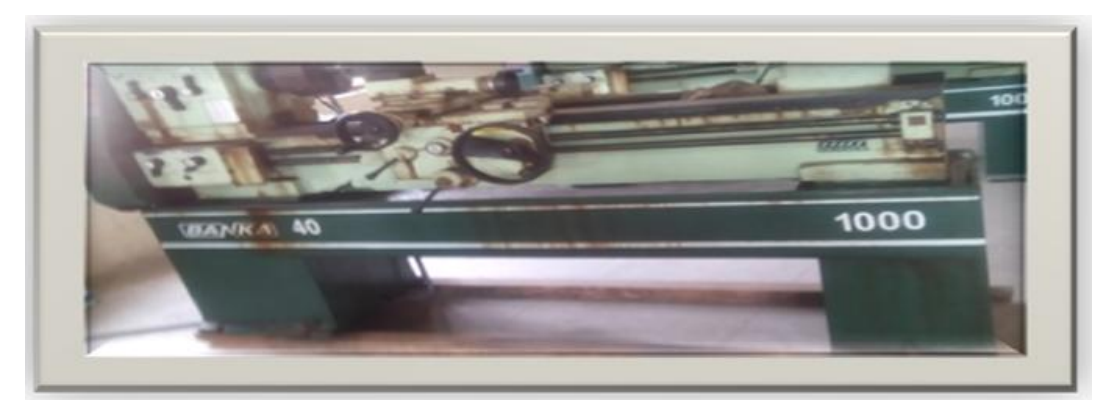

Fig-4: Banka 40 Lathe Machine.

\section{Experimental Procedure}

Turning is popularly used machining process. In this project work turning is done on the lathe machine which is shown in the figure-4.

\subsection{Taguchi Approach:}

The Taguchi method is a well-known technique that provides a systematic and efficient methodology for process optimization and this is a powerful tool for the design of high quality systems. Signal to noise ratio and orthogonal array are two major tools used in robust design. The $\mathrm{S} / \mathrm{N}$ ratio for each level of process parameters is computed based on the S/N analysis. The optimal level of the process parameters is the level having highest $\mathrm{S} / \mathrm{N}$ ratio. The $\mathrm{S} / \mathrm{N}$ ratio characteristics can be divided into three categories when the characteristic is continuous.

a) Nominal is the best

b) Smaller the better

c) Larger is better characteristics.

Alloy steels require smooth surface finish. So quality characteristic chosen for this project work is surface roughness. Since the requirement is to reduce the surface roughness to improve the performance of selected work piece materials, the objective function is of the smaller-the-better type Signal to Noise Ratio: Smaller is better

$$
\text { nS/N ratio }(\eta)=-10 \log _{10}\left[(1 / \mathrm{n}) \square \mathrm{y}_{\mathrm{i}}{ }^{2}\right] \quad \mathrm{i}=1
$$

Where

n: no. of tests in trial (no. of repetitions regardless of noise levels)

$\mathrm{Y}_{\mathrm{i}}$ : is the $\mathrm{i}^{\text {th }}$ observation of the quality characteristic.

\subsection{Taguchi Orthogonal Array:}

$\mathrm{L}_{9}\left(3^{4}\right)$ Orthogonal array is selected for experimentation. This $\mathrm{L}_{9}\left(3^{4}\right)$ orthogonal array is selected from the Taguchi's standard orthogonal arrays. By using this method number of experiments reduced to 9 instead of 27 with almost same accuracy. The Taguchi's standard orthogonal arrays are tabulated in the table-3

Table - 3: Standard $\mathrm{L}_{9}\left(3^{4}\right)$ O.A. Design

\begin{tabular}{|l|l|l|l|l|}
\hline Factors & & & & \\
Expt.No. & 1 & 2 & 3 & 4 \\
\hline 1 & 1 & 1 & 1 & 1 \\
2 & 1 & 2 & 2 & 2 \\
3 & 1 & 3 & 3 & 3 \\
\hline 4 & 2 & 2 & 3 & 3 \\
5 & 2 & 3 & 1 & 1 \\
6 & 3 & 1 & 3 & 2 \\
\hline 7 & 3 & 1 & 3 & 2 \\
8 & 3 & 2 & 1 & 3 \\
9 & 3 & 3 & 2 & 1 \\
\hline
\end{tabular}


In $\mathrm{L}_{9}\left(3^{4}\right)$ orthogonal array, five columns bearing the numbers ' 1 ', '2', '3', '4', represents factors. And each set of numbers below these columns represent levels of that factors respectively. As the index in the first column depicts, each row represents an experiment.

Table - 4: Factor assignment (Experimental Design)

\begin{tabular}{|c|c|c|c|c|}
\hline Factors & $\begin{array}{l}\text { Cutting } \\
\text { speed }\end{array}$ & Feed rate & Depth of cut (mm) & Cutting \\
\hline 1 & (levels) & (levels) & (levels) & (levels) \\
\hline 2 & 455 & 150 & 0.8 & Sherol ENF \\
\hline 3 & 455 & 175 & 1.2 & Straight cutting oil \\
\hline 4 & 683 & 110 & 0.8 & Straight cutting oil \\
\hline 5 & 683 & 150 & 1.2 & Sherol B \\
\hline 6 & 683 & 175 & 0.4 & Sherol ENF \\
\hline 7 & 1025 & 110 & 1.2 & Sherol ENF \\
\hline 8 & 1025 & 150 & 0.4 & Straight cutting oil \\
\hline 9 & 1025 & 175 & 0.8 & Sherol B \\
\hline
\end{tabular}

\subsection{Measurement Of Surface Roughness:}

In this project stylus type surface roughness meter was used to measure the surface roughness of the specimens. There were two main reasons behind selecting stylus type surface roughness one is its easy availability and other is the ease with which it can be operated. The surface roughness measuring instrument used in this experiment is Talysurf.

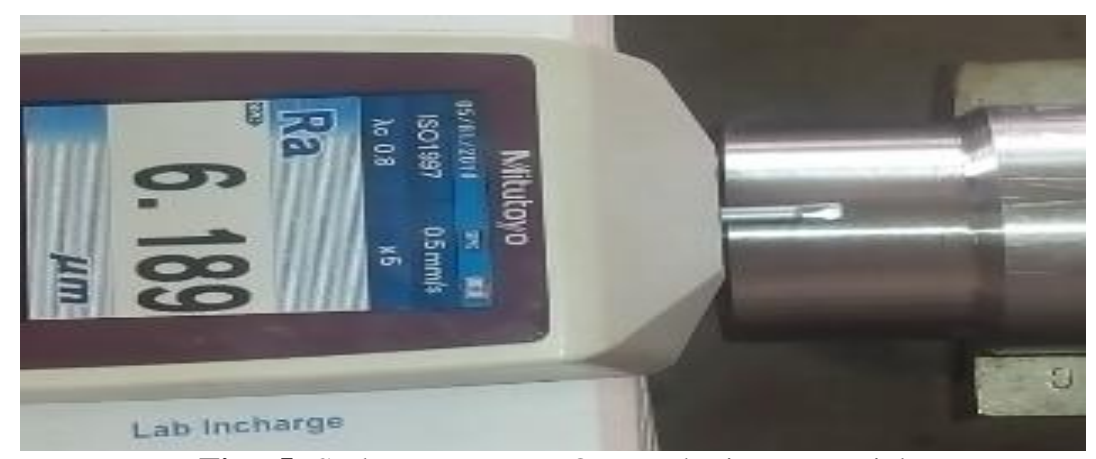

Fig - 5: Stylus Movement On Work piece Material

\subsection{Procedure Followed To Measure Surface Roughness (Ra):}

For each and every experiment the surface roughness of the machined work material is found out. Three points on the work material are considered for each sample and each measurement is about 90 degrees apart. The stylus moves to and fro on the work material at these four points. The $\mathrm{R}_{\mathrm{a}}$ values are displayed on the digital meter and the three values of $R_{a}$ are considered for that particular experiment. Similarly $27\left(R_{a}\right)$ values are considered for 9 experiments.

\section{Results And Analysis}

Minitab statistical software has been used for the analysis of the experimental work. The Minitab software studies the experimental data and then provides the calculated results of signal-to-noise ratio. The average value of $\mathrm{S} / \mathrm{N}$ ratios has been calculated to find out the effects of different parameters and as well as their levels. The Minitab software studies provide the predicted equations of surface roughness for a work piece material. After analysis of data for the surface roughness based on the factors cutting speed, feed rate, depth of cut, cutting fluid for a work piece material i.e., AISI 316 stainless steel is given below.

\section{Starting Minitab 17:-}

Step1: Open minitab15 software and a window is displayed on the desktop as shown below. 


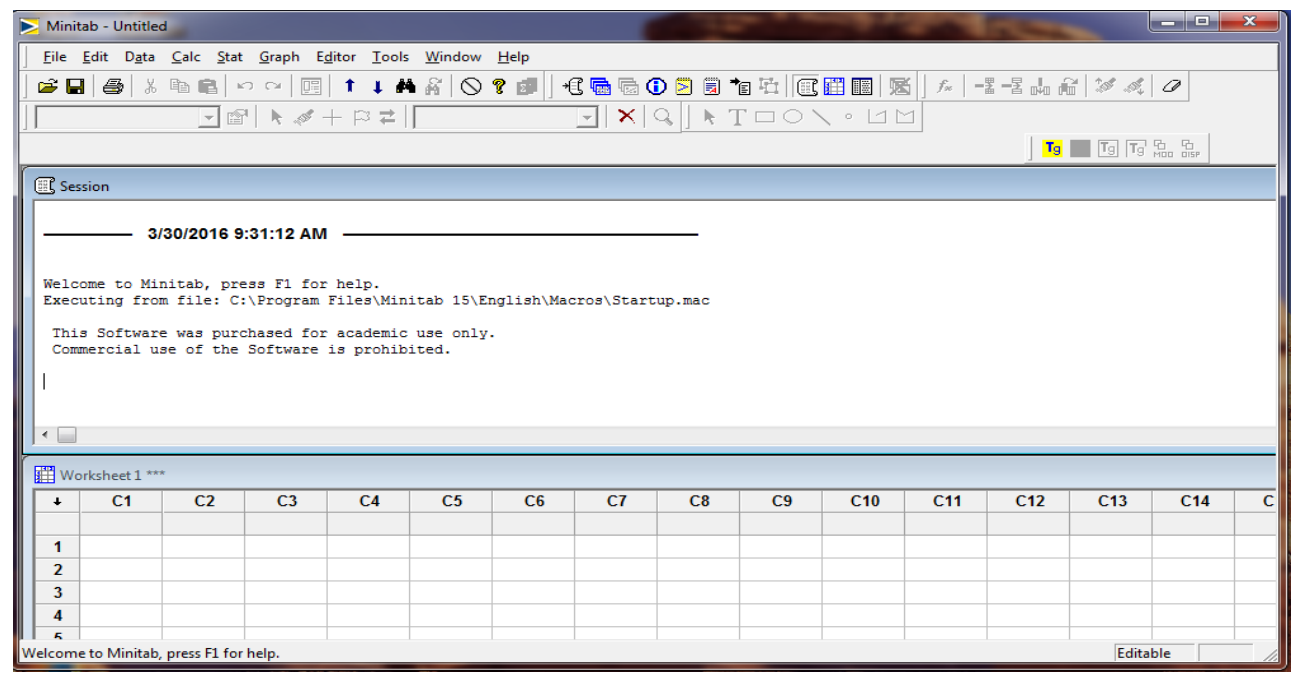

Step 2: Firstly inorder to get results from minitab software by taguchi method we need to define the parameters considerd and obtained experimental values. And by going on clicking as the procedure shown below completes the defining procedure in minitab software.

Click on STAT > DOE $>>$ TAGUCHI $>$ DEFINE CUSTOM TAGUCHI DESIGN...

The window as shown in the figure below

\section{Defining the custom Taguchi design}

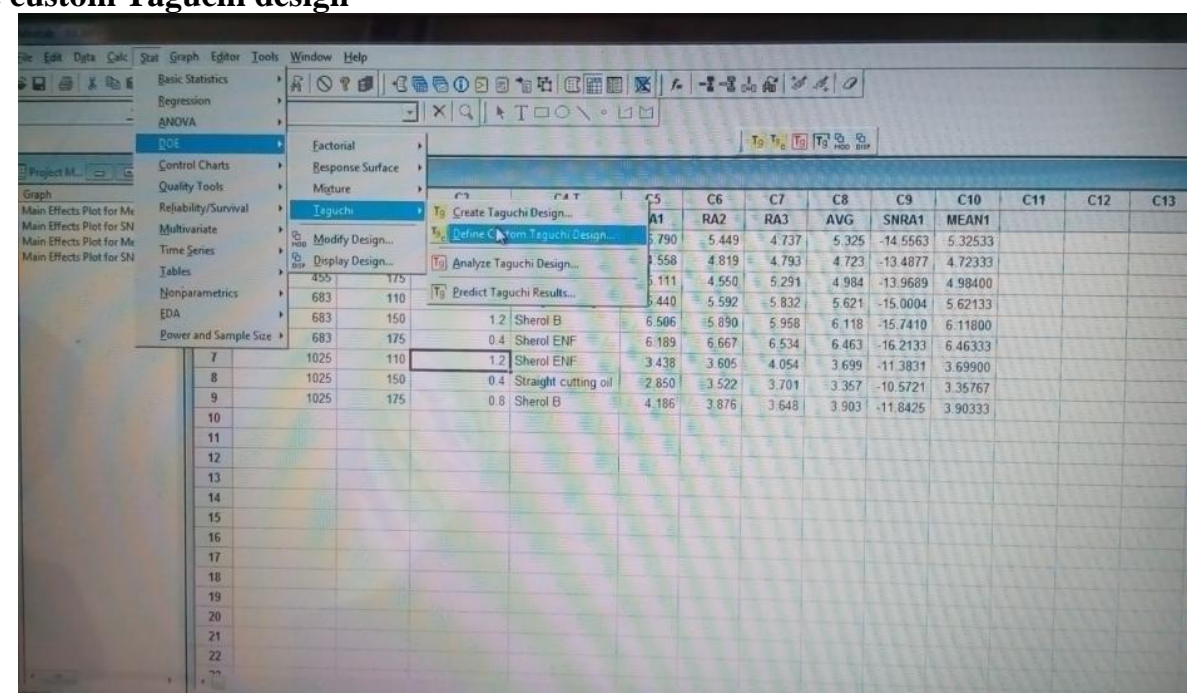

Now various steps involved in getting the final results are as shown in the figures below.

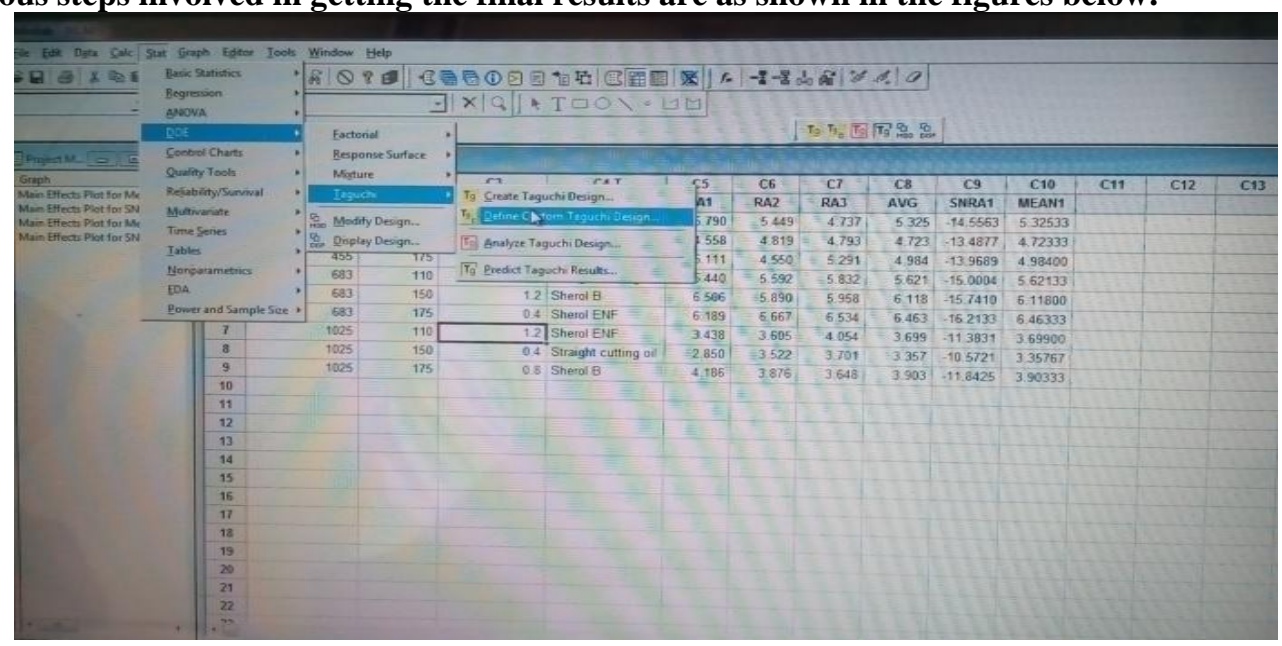



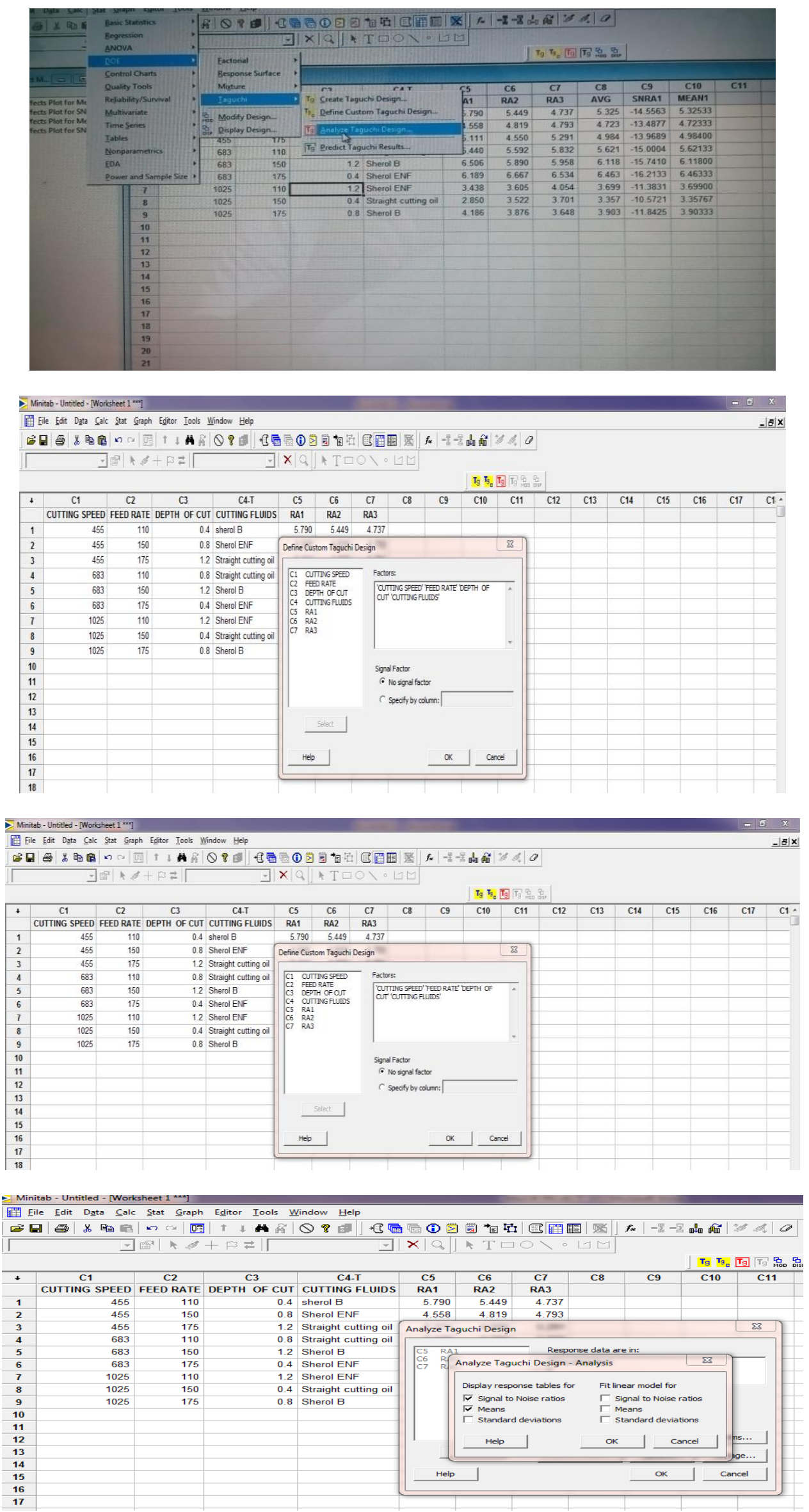


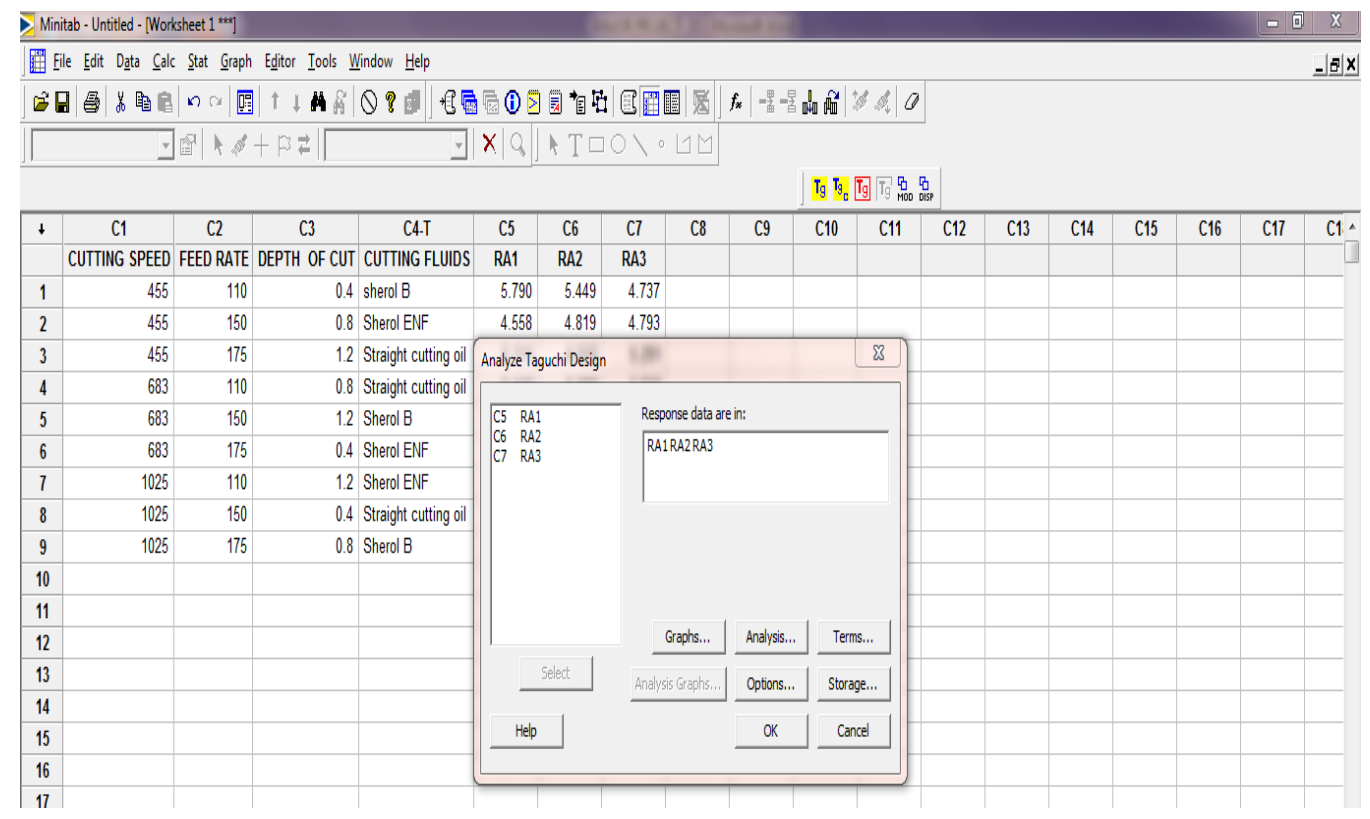

Table - 5: Data Summary of Surface Roughness and S/N Ratio

\begin{tabular}{|l|l|l|l|l|l|}
\hline \multirow{2}{*}{$\begin{array}{l}\text { EXPT. } \\
\text { NO. }\end{array}$} & \multicolumn{4}{|l|}{ SURFACE ROUGHNESS $\left(\mathrm{R}_{\mathrm{a}}\right)(\mu \mathrm{m})$} & \multicolumn{1}{l}{\begin{tabular}{l} 
S/N \\
\cline { 2 - 5 }$(\mathrm{dB})$
\end{tabular}} \\
\hline 1 & 1 & 2 & 2 & Avg. & \\
2 & 5.790 & 5.449 & 4.737 & 5.325 & $\eta_{1}=-14.00$ \\
3 & 4.558 & 4.819 & 5.291 & 4.723 & $\eta_{2}=-13.48$ \\
\hline 4 & 5.111 & 4.550 & 5.291 & 4.984 & $\eta_{3}=-13.96$ \\
5 & 5.440 & 5.592 & 5.832 & 5.621 & $\eta_{4}=-15.00$ \\
6 & 6.506 & 5.890 & 5.958 & 6.118 & $\eta_{5}=-15.74$ \\
7 & 6.189 & 6.667 & 6.534 & 6.463 & $\eta_{6}=-16.21$ \\
8 & 3.438 & 3.605 & 4.054 & 3.699 & $\eta_{7}=-11.38$ \\
9 & 2.850 & 3.522 & 3.701 & 3.357 & $\eta_{8}=-10.57$ \\
\hline
\end{tabular}

\section{Selection Of Optimum Set Of Conditions:}

The objective is to maximize the $\mathrm{S} / \mathrm{N}$ ratio, hence select the factor levels which have maximum $\mathrm{S} / \mathrm{N}$ ratio values. The best condition for cutting speed factor is level 3, $96.6(\mathrm{~m} / \mathrm{min})(1025 \mathrm{rpm})$, for feed is level 2 $(150 \mathrm{~mm} / \mathrm{rev})$, for depth of cut is level $2,(0.8 \mathrm{~mm})$, for cutting fluids is level 3 i.e., straight cutting oil. Thus optimum conditions chosen were: $\mathrm{A}_{3}-\mathrm{B}_{2^{-}} \mathrm{C}_{2}-\mathrm{D}_{3}$ combination. The optimum set of control factors are shown in table.

Table - 6: Maximum S/N Ratios for each factor

\begin{tabular}{|l|l|l|l|}
\hline & LEVE1 & LEVEL2 & LEVEL3 \\
\hline FACTOR & -14.00 & -15.65 & $\mathbf{- 1 1 . 2 7}$ \\
\hline FEED (B) & -13.65 & $\mathbf{- 1 3 . 2 7}$ & -14.01 \\
\hline DEPTH OF CUT(C) & -13.78 & $\mathbf{- 1 3 . 4 4}$ & -13.70 \\
\hline CUTTINGFLUIDS(D) & -14.05 & -13.69 & $\mathbf{- 1 3 . 1 8}$ \\
\hline
\end{tabular}

Prediction Of Process Average For Optimum Condition:

Having determined the optimum condition from the orthogonal array experiment, the next step is to predict the anticipated process average $\eta$ predicted under Chosen optimum condition. This is calculated by summing the effects of factor levels in the optimum condition.

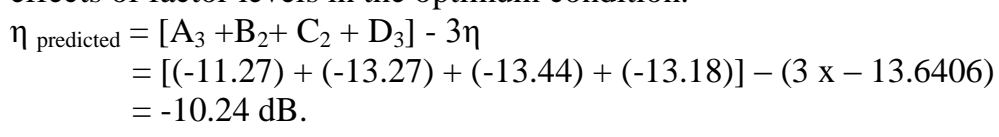

Table - 7: Optimized Cutting Parameters

\begin{tabular}{|l|l|}
\hline$\eta_{\text {predicted }}(\mathrm{dB})$ & $\mathbf{- 1 0 . 2 4} \mathbf{d B}$. \\
\hline$\eta_{\text {confirmation test }}(\mathrm{dB})$ & $\mathbf{- 1 1 . 0 3 5} \mathbf{d B}$. \\
\hline
\end{tabular}


Table - 8: Conformation Test Results

\begin{tabular}{|l|l|l|l|l|}
\hline \multicolumn{3}{|l|}{ SURFACE ROUGHNESS(Ra) $(\mu \mathrm{m})$} & $\begin{array}{l}\text { S/N RATIO } \\
(\mathrm{dB})\end{array}$ \\
\hline 1 & 2 & 3 & Avg. & $\mathbf{- 1 1 . 0 3 5}$ \\
\hline 3.104 & 3.231 & 3.116 & 3.150 & \\
\hline
\end{tabular}

The $\mathrm{S} / \mathrm{N}$ ratio of predicted value and verification test values were compared for validity of the optimum condition. It is found that the $\mathrm{S} / \mathrm{N}$ ratio value of verification test is within the limits of the predicted value and the objective is fulfilled. As the conformation and projected improvements matched, suggested optimum conditions can be adopted. $\mathrm{S} / \mathrm{N}$ ratio is calculated by using the formula given below.

Table - 9: Comparison of S/N Ratios

\begin{tabular}{|l|l|l|l|l|l|}
\hline Control Factor & $\begin{array}{l}\text { Cutting Speed (A) } \\
(\mathbf{m} / \mathbf{m i n})(\mathbf{r p m})\end{array}$ & $\begin{array}{l}\text { Feed (B) } \\
(\mathbf{m m} / \mathbf{r e v})\end{array}$ & $\begin{array}{l}\text { Depth of cut (C) } \\
(\mathbf{m m})\end{array}$ & Cutting fluids \\
\hline Optimum value & $\begin{array}{l}96.6 \mathrm{~m} / \mathrm{min} \\
(1025 \mathrm{rpm})\end{array}$ & 150 & 0.8 & Straight cutting oil \\
\hline
\end{tabular}

\section{Conclusions}

$>$ The best condition for cutting speed factor is level 3 (96.6 m/min)(1025 rpm), for feed is level 2 (150 $\mathrm{mm} / \mathrm{rev})$, for depth of cut is level $2(0.8 \mathrm{~mm})$, straight cutting oil in cutting fluids in level 3 for work piece material AISI stainless steel.

$>$ The graph below shows the main effect plot for $\mathrm{S} / \mathrm{N}$ ratios. The values on the $\mathrm{x}$-axis are various cutting parameters and their three different values used in three different levels. And the $y$-axis contains mean of $\mathrm{S} / \mathrm{N}$ ratios. Each cutting parameter's optimum values are discussed below.

$>$ Cutting speed: From the graph shown below, since the $\mathrm{S} / \mathrm{N}$ ratio is larger at cutting speed 1025, then it is said to be the optimum cutting speed.

$>$ Feed rate: from the graph below, it shows that the $\mathrm{S} / \mathrm{N}$ ratio is larger at feed rate 150 , and then the optimum feed rate is 150 .

$>$ Depth of cut: As shown in the graph below it is clear that the $\mathrm{S} / \mathrm{N}$ ratio is larger at depth of cut 0.8 . Then the optimum depth of cut is 0.8 .

$>$ Cutting fluid: It is clear that the $\mathrm{S} / \mathrm{N}$ ratio is larger at cutting fluid, straight cutting oil. Then we can say that the optimum cutting fluid is straight cutting oil. It means that the values we got by using straight cutting oil are optimum values.

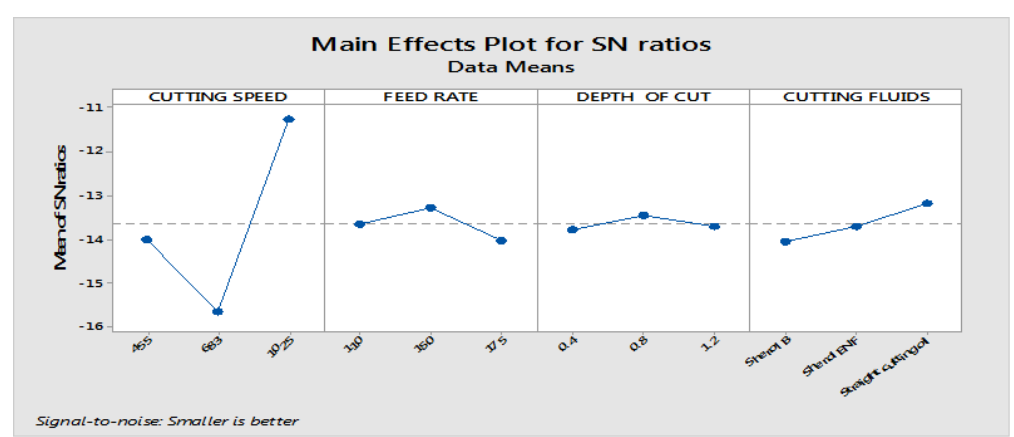

Fig - 6: Graphs of main effects plot for $\mathrm{S} / \mathrm{N}$ ratios for surface roughness.

Main effect plots for surface roughness are shown in the figure2.1. Main effect plot shows the variation of surface roughness with respect to cutting speed, feed rate and depth of cut and cutting fluids. X axis represents change in level of the variable and y axis represents the change in the resultant response.

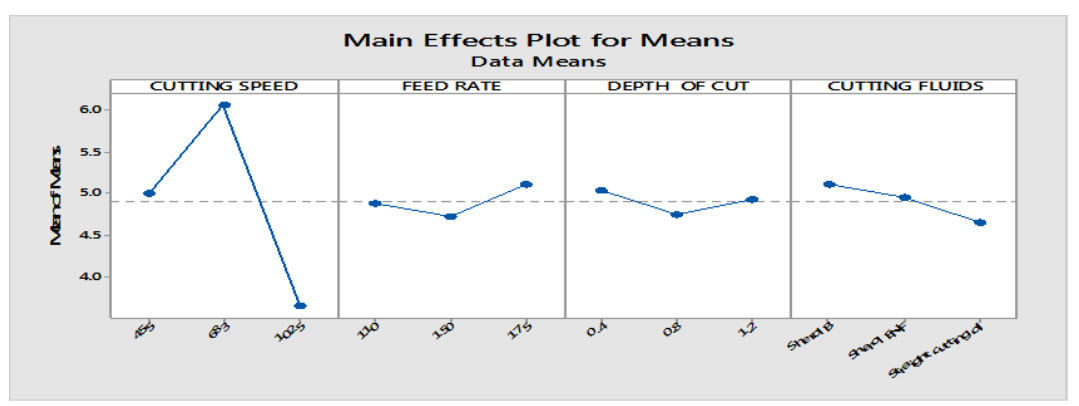

Fig - 7: Graphs of Main effects plot for means for surface roughness. 


\section{References}

[1] Alagarsamy.S.V, Raveendran.P, Arockia Vincent Sagayaraj.S, Tamil Vendan.S. Optimization of machining parameters for Turning of Aluminium alloys 7075 using Taguchi method, International Research Journal of Engineering and Technology (IRJET) 2016.

[2] Ch.Maheswara Rao, K. Venkatasubbaiah, Optimization of Surface Roughness in CNC Turning Using Taguchi Method and ANOVA, International Journal of Advanced Science and Technology, 93, 2016, 1-14.

[3] Mohd. Abbas, Sravan Kumar, Atishey Mittal, optimization of Cutting Parameters to improve Surface Roughness of AL 1070 in Turning Operation using Taguchi Method, International Journal of Engineering Sciences \& Research Technology, 5(7), 2016, 2277-9655.

[4] Abhishek Prakash, Optimization of Machining Parameters of EN36C Steel in CNC Turning By Use of Taguchi Approach, Imperial Journal of Interdisciplinary Research, 2(5), 2016, 2454-1362.

[5] Narendra Kumar Verma, Ajeet Singh Sikarwar, Optimizing Turning Process by Taguchi Method Under Various Machining Parameters, International Research Journal of Engineering and Technology (IRJET), 2(6), 2015.

[6] Sachin C Borse, optimization of turning Process Parameter in dry Turning of SAE 52100 Steel, International journal of Mechanical Engineering and technology, 5(12), 2014, 01-08.

[7] Narayana B. Doddapattar, Chetana S. Batakurki Optimazation Of Cutting Parameters For Turning Aluminium Alloys Using Taguchi Method, International Journal of Engineering Research \& Technology (IJERT,) 2(7), 2013

[8] Vishnu D Asal, Chintan A Prajapati Optimization of Turning Process Using Design of Experiment. Indian Journal of Research 2(4) April 2013.

[9] M. Aruna and V. Dhanalaksmi, Design Optimization of Cutting Parameters when Turning Inconel 718 with Cermet Inserts, International Journal of Mechanical and Aerospace Engineering, 2012.

[10] Krishankant, Jatin Taneja, Mohit Bector, Rajesh Kumar. Application of Taguchi Method for Optimizing Turning Process by the effects of Machining Parameters. International Journal of Engineering and Advanced Technology, 2(1),2012, 2249 - 8958.

[11] S Thamizhmanii, S.Saparudin, S. Hasan, Analysis of surface Roughness by Turning Process using Taguchi method, Journal of achievements in Materials and Manufacturing Engineering, 20(2), 2007. 